\title{
Effect of Ultrasound and Xylanase Treatment on the Physical-Mechanical Properties of Bleached Eucalyptus Kraft Pulp
}

\author{
Larisse Ribas Batalha ${ }^{1}$, Juliana da Silva ${ }^{1}$, Carolina Jardim $^{2}$, Rubens Oliveira ${ }^{1}$, Jorge Colodette ${ }^{1}$
}

${ }^{1}$ Federal University of Viçosa, Viçosa, Brazil; ${ }^{2}$ Suzano Celulose e Papel SA, Brazil

E-mail: larisse.batalha@ufv.br

Received April $7^{\text {th }}$, 2011; revised April 18 ${ }^{\text {th }}, 2011$; accepted April $25^{\text {th }}, 2011$.

\begin{abstract}
The modification on the fiber structure of bleached eucalyptus kraft pulp is a very attractive alternative for improvements in the properties of paper production. The enzymatic treatment by xylanases and ultrassonic treatments modify the characteristics of the fibers, has been reported. Therefore, the purpose of this study was to evaluate the influence of ultrasonic waves as a facilitator of the action of enzymes (hemicellulase) by modifying the physicochemical nature of fiber eucalyptus Kraft pulp, in order to improve the physical and mechanical properties of the paper. But it was observed the that idea of ultrasound acts as facilitator for action of enzymes can't be affirmed, since in most properties $X A-1$ and XA-2 were equal statistically. It may be noted that the junction of ultrasound and xylanase provided improves on tensile index, specific elastic modulus and tensile energy absorption and a decrease of tear index on the mechanical properties of handsheet and it increased the opacity when the ultrasound was applied before xylanase.
\end{abstract}

Keywords: Ultrasonic, Xylanases, Physical Properties, Mechanical Properties

\section{Introduction}

The modification on the fiber structure of bleached eucalyptus kraft pulp is a very attractive alternative for improvements in the properties of paper production. The enzymatic treatment by xylanases modifies the characteristics of fibers, improvement of hydration, internal fibrillation and delamination has been reported. The ultrasound promotes morphological changes, generating improvements in properties, without the increase of chemicals demand or generation of toxic effluents.

The ultrasonic is defined with a sound of frequency beyond response of human hearing, that is, higher than $16 \mathrm{kHz}$ (1600 cycles per second) [1]. This may produce morphological changes in the fiber which can contribute for a best conformability, flexibility and consolidation of the fibers during paper formation [2]. The xylanases have shown potential for modification of cellulose fibers, promoting improvements in bleachability of kraft pulp [3]. In the bleaching the enzyme acts degrading xylan molecules precipitated (deposited in the fibers at the end of cooking) and cleaving bonds lignin-carbohydrate [4]. Also, it is reported improvements in hydration (swelling), internal fibrillation and delamination due to the enzy- matic treatment of pulp, mediated by xylanases [5].

The effects of ultrasonic on the enzymes aren't very known and ccontradictory results are observed when they are treated at high intensities. Only some enzymes are inactivated by application of ultrasound systems at high intensities, since the sonification doesn't denature all proteins, unlike heat denaturation, which could explain the contradictions with respect to deactivation of the enzymes by sonification [6]. The low intensities of ultrasonics in some cases may increase the activity of free enzymes [7].

So, changes of eucalyptus fiber by ultrasonic and enzymatic treatment have considerable influence in the paper production process and can improve the performance of fiber-fiber and fiber-water interactions. It also contributes to the consolidation of product properties. Therefore, the purpose of this study was to evaluate the influence of ultrasonic waves as a facilitator of the action of enzymes (hemicellulase) by modifying the physicochemical nature of fiber eucalyptus Kraft pulp, in order to improve the physical and mechanical properties of the paper. 


\section{Experimental}

\subsection{Material}

The equipment used to generate ultrasonic waves in this work was the model VIRSONIC 475 with a frequency of $20 \mathrm{kHz}$ using the maximum power of the equipment (190 $\mathrm{W})$. The dosage of xylanases used was $5000 \mathrm{U} / \mathrm{kg}$.

\subsection{Methods}

Three treatments were performed: I) treatment of eucalyptus kraft pulp by ultrasound and subsequent xylanase; II) treatment of eucalyptus kraft pulp by xylanase and subsequent ultrasound treatment; III) treatment of eucalyptus kraft pulp by xylanase only. In the three treatments it was used pulp with consistency of $3 \%$ and $\mathrm{pH}$ range of 7 to 7.5 After the treatments, the cellulose pulps were refined in PFI mill laboratory. For the realization of physico-mechanical and optical tests it was formed laboratory sheets, which are stored in an environment with relative humidity of $50 \pm 2 \%$ and $23 \pm 1{ }^{\circ} \mathrm{C}$ temperature. All procedures and tests were realized according to TAPPI procedures [8]. The treatments were compared statistically.

The adjusted equations were compared by $\mathrm{F}$ test, using the models identity test and adopting a significance level of up to $5 \%$ probability according to the methodology presented by [9] for linear models. The equations were compared in order to check equality between them. If so, the equations were reduced to a single equation. If it had confirmed a significant difference between the equations, it was not tested which differed. The tested hypotheses were: H0: all equations are equal and they may be represented by a common reduced equation, and $\mathrm{H} 1$ : the equations are different statistically and they can't be reduced to a common equation.

\section{Results and Discussion}

\subsection{Nomenclature of Treatments}

XA-1: treatment of eucalyptus kraft pulp by ultrasound and subsequent xylanase;

XA-2: treatment of eucalyptus kraft pulp by xylanase and subsequent ultrasound;

XA-3: treatment of eucalyptus kraft pulp by xylanase only.

\subsection{Refining PFI}

The choice of the number of revolutions is indicated by the degree of drainability of an aqueous suspension of fibers [10]. The equipment used in the Pulp and Paper Laboratory for measuring the degree of drainability is the Schopper-Riegler. This expresses the degree of refining as Schopper-Riegler degree ( $\left({ }^{\circ} \mathrm{SR}\right)$.

Four points of refining were made. In order to obtain a curve to analyze how the properties of paper formed "react" to refining, trying to achieve a value close to 50 ${ }^{\circ} \mathrm{SR}$. The maximum degree Schopper used was $60{ }^{\circ} \mathrm{SR}$. These values are used because many companies that produce paper derived from bleached Kraft pulp employ them. During the refining it is also obtained the energy needed to refine the pulp. In a company the consumption is very important, because it is directly tied to production costs. To study the effect of enzyme treatment and ultrassonification on the consumption energy a graphic was done which relates this with the degree Schopper-Riegler (Figure 1).

Based on the $\mathrm{F}$ test, the hypothesis of equality between equations relating at XA-1 and XA-2 in function of energy consumption was accepted $(\mathrm{P}<0.05)$, and these can be represented by the common model estimated, represented in Figure 1. Therefore XA-1 and XA-2 are statistically equal, thus the order of application of ultrasound and enzyme on pulp didn't provide difference on the energy consumption. However, it can see that the addition of the ultrasonic treatment and enzymatic treatments didn't provide energy consumption when compared to treatment with only the enzyme. This is because when ultrasound is applied before the xylanase promotes fibrillation and leaves the xylans more exposed and thus the xylan are hydrolyzed more easily. The low xylans content affect the pulp hydration decreasing it, thus hindering the refining and increasing the energy consumption. In the case of II treatment in which the xylanase is applied before the ultrasound have that the xylanase hydrolyzes xylans chains and the ultrasound removes xylan deposited on the surface layer of the fiber. So content of xylans also will be lower, therefore, becoming the refining difficult.

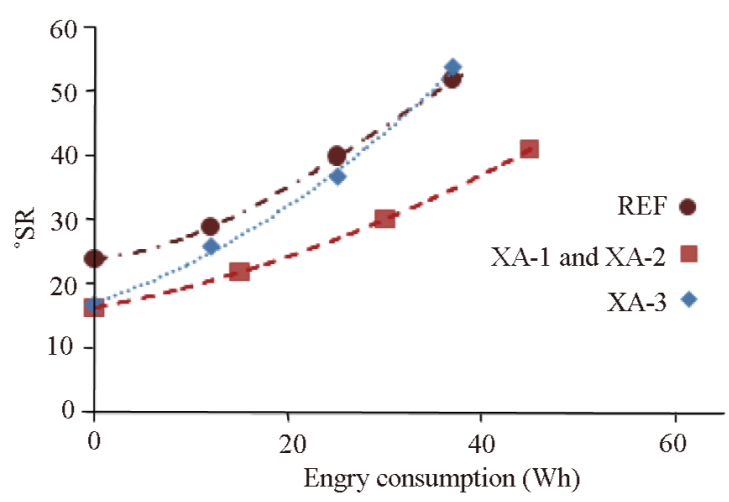

REF: $\hat{y}=-0.0003 x^{3}+0.0282 x^{2}+0.1211 x+24, R^{2}=100$

XA-1 and XA-2: $\hat{y}=0.006^{2}+0.2797 x+16.4$ (common model), $R^{2}=98.98$

XA-3: $\hat{y}=0.01333 x^{2}+0.4898 x+17313, R^{2}=99.77$

Figure 1. Schopper-Riegler ( $\left.{ }^{\circ} \mathrm{SR}\right)$ versus energy consumption. Below the estimated equations for each treatment. 
If loss of hemicelluloses occur the hydration of the pulp becomes smaller, thus to achieve determined higher Schopper-Riegler degree it would be necessary to intensify the refining, this it may be observed in the treated pulp with xylanase (XA-3) when it is considered the enzyme effect (zero point of the refining), SchopperRiegler degree found was lower than the reference.

\subsection{Physical and Mechanical Properties}

\subsubsection{Tensile Index}

The tensile strength is related to the durability and utility of the paper, for example, packaging papers are subject to direct tension forces. This is favored by intensity of interfibrillar links occurred during the formation of the paper, the external fibrillation and the collapse of the fibers [10].

For the $\mathrm{F}$ test, the hypothesis of equality between equations relating at XA-1 and XA-2 in function of energy consumption was accepted $(\mathrm{P}<0.05)$, and these can be represented by the common model estimated, represented in Figure 2.

The xylanase removes superficial hemicelluloses which decrease the interfibers links, consequently, the tensile index, since this favored by intensity of interfibrillar links. Therefore, the treatment III has a tensile index lower than the reference.

XA-1 and XA-2 were statistically equal. This shows that the ultrasound acts superficially increasing the extern fibrillation, hence, raises the tensile index.

During the tensile tests force-deformation relations are produced and through these relations the properties of specific elastic modulus (MOE) and tensile energy absorption (TEA) will be derived. MOE is an important property because they represent the capacity of the mate-

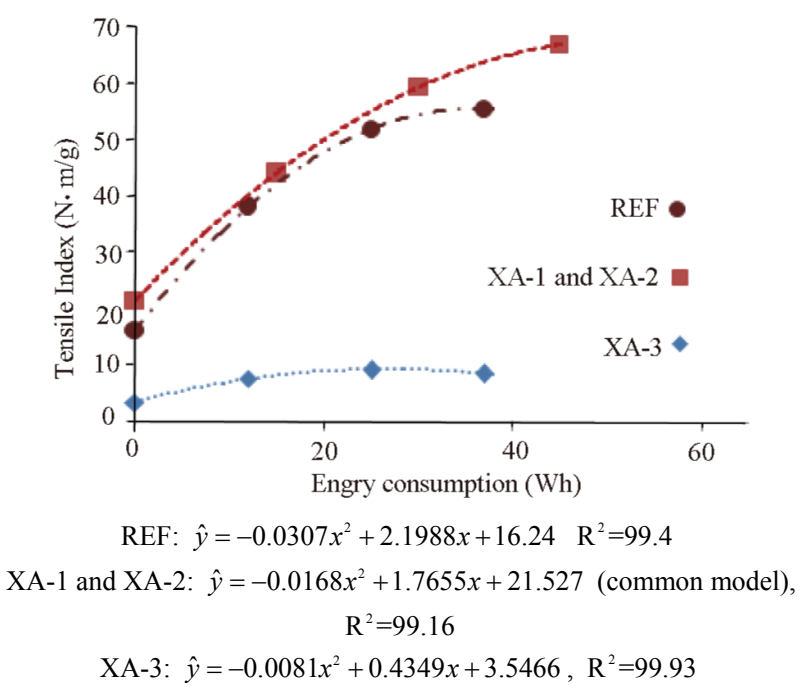

Figure 2. Tensile index versus energy consumption. Below the estimated equations for each treatment. rial to absorb force without, however, suffering substantial deformation. The TEA represents the durability of paper when subjected to repetitive use, under conditions of tensile or impact. In this work it was observed that the joint of enzymatic and ultrasonic treatment resulted in additional properties MOE and TEA in relation to initial pulp. It was found an increase of $48.0 \%$ and $12.1 \%$ for TEA and MOE, respectively.

\subsubsection{Tear Index}

The tear resistance measures the work required to tear the paper. The length of the fiber and the link between them are factors that may affect the resistance for the tearing [10].

The $\mathrm{F}$ test showed that the hypothesis of equality between equations relating at XA-1 and XA-2 in function of energy consumption is accepted $(\mathrm{P}<0.05)$, and these can be represented by the common model estimated, represented in the Figure 3.

It was observed the treatment of pulp with xylanase only decreases the tear index. This fact may be explained by action of xylanase that reduces the intrinsic fibrillar resistance due to removal of superficial hemicelluloses. It also noted that the ultrasound doesn't compromise the fibrillar wall, and the increase observed in relation to the reference reinforces the idea of fibrillation.

\subsection{Optical Property}

\subsubsection{Opacity}

Opacity is an optical property that is related to the amount of light transmitted through the paper [10], therefore, with phenomena of refraction, dispersion and absorption. Thus, the greater the amount of void spaces, the greater the amount of surface refraction, dispersion and absorption, and the lower the amount of light transmitted to the opposite side of the paper and the greater the opac-

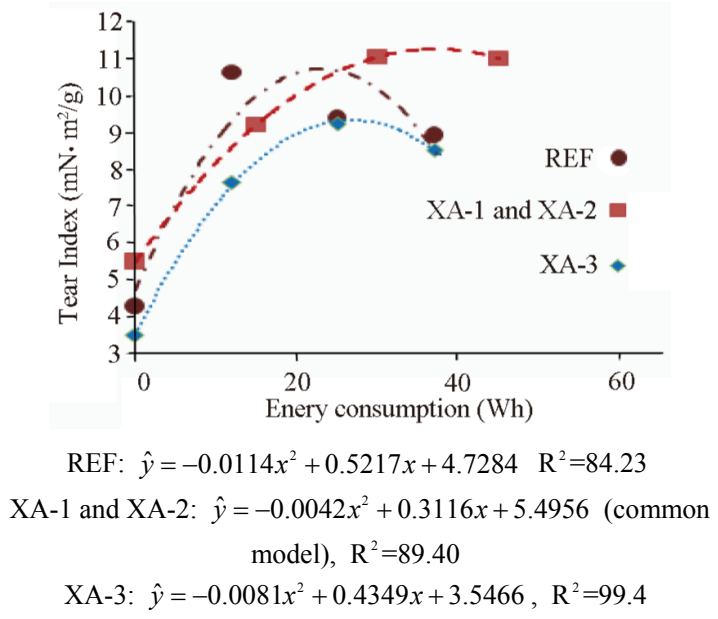

Figure 3. Tear index versus energy consumption. Below the estimated equations for each treatment. 
ity of the paper.

By $F$ test applied to treatments it was found that the hypothesis of equality between equations relating to REF and XA-3 in function of energy consumption is accepted $(\mathrm{P}<0.05)$, and these can be represented by the common model estimated, represented in Figure 4.

It was observed that the xylanase didn't act to the point of causing alteration significant in the opacity. The hydrolyzed xylan by enzyme and removed by ultrasound (XA-2) caused an increase on bulk, which reflected in rising of opacity (in relation to REF) provides higher strength to light transmission. The figure of apparent specific volume is represented in Figure 5.

The ultrasound due to direct effect in of resonance loosens the fibrillar wall, and consequently, reduces

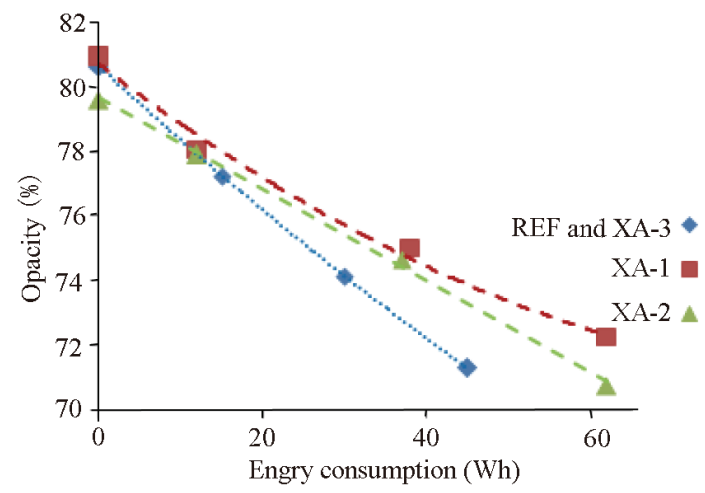

REF and XA-3: $\hat{y}=0.0006 x^{2}-0.2352 x+80.657$, (common model),

$$
\begin{gathered}
\mathrm{R}^{2}=95.27 \\
\text { XA-1: } \hat{y}=0.0011 x^{2}-0.194 x+80.70, \mathrm{R}^{2}=99.10 \\
\text { XA-2: } \hat{y}=-0.1415 x+79.66, \mathrm{R}^{2}=99.84
\end{gathered}
$$

Figure 4. Opacity versus energy consumption. Beside the estimated equations for each treatment.

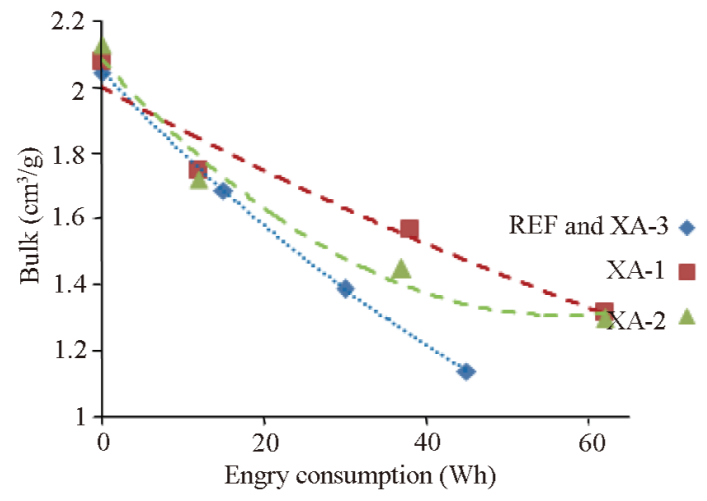

REF and XA-3: $\hat{y}=2.0479 e^{-0.013 x},($ common model $), \mathrm{R}^{2}=85.48$

$$
\text { XA-1: } \hat{y}=2.0023 e^{-0.007 x}, \mathrm{R}^{2}=95.87
$$

$\mathrm{XA-2}: \hat{y}=0.0002 x^{2}-0.0276 x+2.0898, \mathrm{R}^{2}=97.60$

Figure 5. Opacity versus energy consumption. Beside the estimated equations for each treatment.

density of fibers [11]. The subsequent action of xylanase causes stiffness due to loss of xylans, which during the refining process result in a greater formation of thins and these to take up spaces interfibrillar increase the opacity of the paper formed.

\section{Conclusions}

The purpose of this study was to evaluate the influence of ultrasonic waves as a facilitator of the action of enzymes (hemicellulases) by modifying the physicochemical nature of fiber eucalyptus Kraft pulp, in order to improve the physical and mechanical properties of the paper. But it was observed that the idea of ultrasound acts as facilitator of action of enzymes can't be affirmed, since in most properties of XA-1 and XA-2 were equals statistically. But, it was noticed that the junction of ultrasound and xylanase provided improves on tensile tensile index, specific elastic modulus and tensile energy absorption and a decrease of tear index on the mechanical properties of handsheet and increased the opacity when the ultrasound was applied before xylanase.

\section{Acknowledgements}

Financial support provided by the Minas Gerais State Research Foundation (Fapemig) is greatly appreciated

\section{REFERENCES}

[1] Y. T. Shah, A. B. Pandit and V. S. Moholkar, "Cavitation Reaction Engineering”, Springer, 1999, pp. 96-106.

[2] A. M. Tang, H. W. Zhang, G. Chen, G. H. Xie and W. Z. Liang, "Influence of Ultrasound Treatment on Accessibility and Regioselective Oxidation Reactivity of Cellulose," Ultrasonics Sonochemistry, Vol. 12, 2005, pp. 467472. doi:10.1016/j.ultsonch.2004.07.003

[3] P. J. Gerber, J. A. Heitmann, T. W. Joyce, J. Buchert, M. Siika-aho,"Adsorption of Hemicallulases onto Bleached Kraft Fibers,” Journal of Biotechnology, Vol. 67, 1999, pp. 67-75. doi:10.1016/S0168-1656(98)00163-1

[4] A. H. Manji, "Extended Usage of Xylanase Enzyme to Enhance the Bleaching of Softwood Kraft," Tappi Journal, Vol. 5, No. 1, 2006, pp. 23-26.

[5] P. Bajpai, S. P. Mishra, O. M. Mishra, S. Kumar and P. K. Bajpai, "Use of Enzymes for Reduction in Refining Energy - Laboratory Studies," Tappi Journal, Vol. 5, No 11, 2006, pp. 25-32.

[6] D. Guzey, H. J. Kim and D. J. McClements, "Factors Influencing the Production of O/W Emulsions Stabilized by $\beta$-Lactoglobulin-Pectin Membranes," Food Hydrocolloids, Vol. 18, 2005, pp. 967-975. doi:10.1016/j.foodhyd.2004.04.001

[7] M. H. Entezari and C. Pétrier, "A Combination of UltraSound and Oxidative Enzyme: Sonobiodegradation of Substituted Phenols," Ultrasonics Sonochemistry, Vol. 10, 
2003, pp.241-246. doi:10.1016/S1350-4177(03)00087-7

[8] Tappi Standard Procedures. Tappi Press. Atlanta, 1998.

[9] A. J. Regazzi, "Teste Para Verificar a Identidade de Modelos de Regressão e a igualdade de Alguns Parâmetros num Modelo Polinomial Orthogonal," Revista Ceres, Vol. 40, No. 228, 1993, pp. 176-195.

[10] M. L. O. D'Almeida,'Technology of papermaking," IPT, São Paulo, 1988.

[11] J. C. Silva, “Application of enzymes, extraction and addition of hemicellulases combined with ultrasonic waves for development of properties of recycled papers," Master's degree Dissertation, Federal University of Viçosa, Viçosa, 2011. 